\title{
Genome-Wide Expression Profiling of the Retinoschisin-Deficient Retina in Early Postnatal Mouse Development
}

\author{
Andrea Gebrig, ${ }^{1,2}$ Thomas Langmann, ${ }^{2}$ Franziska Horling, ${ }^{2}$ Andreas Janssen, ${ }^{2}$ \\ Michael Bonin, ${ }^{3}$ Michael Walter, ${ }^{3}$ Sven Poths, ${ }^{3}$ and Bernhard H. F. Weber ${ }^{2}$
}

Purpose. The $R s 1 b$ knockout mouse displays retinal features typical for X-linked juvenile retinoschisis (RS). Consequently, this mouse line represents an excellent model to study early molecular events in RS.

Methods. Whole genome expression profiling using DNA-microarrays was performed on total RNA extracts from retinoschisin-deficient and wild-type murine retinas from postnatal days 7, 9, 11, and 14. Quantitative real-time RT-PCR (qRT-PCR) analysis of additional time points facilitated the refinement of the temporal expression profile of differentially regulated transcripts. Differential protein expression was confirmed by Western blot analysis.

Results. Based on biostatistic and knowledge-based DNA-microarray analyses we have identified differentially regulated retinal genes in early postnatal stages of the $R s 1 b$-deficient mouse defining key molecular pathways including adhesion, cytoskeleton, vesicular trafficking, and immune response. A significant upregulation of Egr1 at P11 and several microglia/ glia-related transcripts starting at P11 with a peak at P14 were identified in the diseased retina. The results provided evidence that macrophage/microglia activation precedes apoptotic photoreceptor cell death. Finally, the role of Egr1 in the pathogenesis of $R s 1 b$-deficiency was investigated, and the results indicated that activation of the MAPK Erk1/2 pathway occurs as early as P7. Analyses of $R s 1 b^{-/ Y} / E g r 1^{-/-}$double-knockout mice suggest that Egr1 upregulation is not a prerequisite for macrophage/microglia activation or apoptosis.

Conclussons. The findings imply that microglia/glia activation may be triggering events in the photoreceptor degeneration of retinoschisin-deficient mice. Furthermore, the data point to a role of Erk1/2-Egr1 pathway activation in RS pathogenesis. (Invest Ophthalmol Vis Sci. 2007;48:891-900) DOI:10.1167/ iovs.06-0641

From the ${ }^{1}$ Institute of Human Genetics, University of Würzburg, Würzburg, Germany; the ${ }^{2}$ Institute of Human Genetics, University of Regensburg, Regensburg, Germany; ${ }^{3}$ Institute of Anthropology and Human Genetics, University of Tübingen, Tübingen, Germany.

Supported by Grant WE 1259/12-3 from the Deutsche Forschungsgemeinschaft (BHFW), the Interdisciplinary Center of Clinical Research Tübingen (IZKF), and Grant 01KS9602 from the Federal Ministry of Education and Research (MB).

Submitted for publication June 13, 2006; revised August 23 and October 12, 2006; accepted December 18, 2006.

Disclosure: A. Gehrig, None; T. Langmann, None; F. Horling, None; A. Janssen, None; M. Bonin, None; M. Walter, None; S. Poths, None; B.H.F. Weber, None

The publication costs of this article were defrayed in part by page charge payment. This article must therefore be marked "advertisement" in accordance with 18 U.S.C. $\$ 1734$ solely to indicate this fact

Corresponding author: Bernhard H. F. Weber, Institute of Human Genetics, University of Regensburg, Franz-Josef-Strauss-Allee 11, D-93053 Regensburg, Germany; bweb@klinik.uni-regensburg.de.
$\mathbf{R}$ etinoschisis (RS) is a recessively inherited retinal dystrophy with macular disease often resulting in early-onset vision loss. A hallmark of the disease is a limited splitting of the central retina typically presenting as a spoke-wheel pattern. ${ }^{1}$ Peripheral schisis is seen in approximately $50 \%$ of affected males and is usually located in the inferior temporal quadrant. $\mathrm{RS}$ is caused by loss-of-function mutations in the RS1 gene on $\mathrm{Xp} 22.13{ }^{2}$ It encodes a $24-\mathrm{kDa}$ protein, termed retinoschisin, which is mainly secreted from photoreceptors as a homooligomeric complex. ${ }^{3-7}$ Retinoschisin is almost entirely composed of a highly conserved discoidin domain frequently found in a wide range of membrane and extracellular proteins and most likely mediating cell adhesion and cellular signaling processes. ${ }^{8,9}$

To study retinoschisin function, we have generated a genetargeted mouse line with a disruption of $R s 1 \mathrm{~h}$, the murine orthologue of the human RS1 gene. ${ }^{10}$ The knockout mouse appears to be an excellent disease model that closely resembles human disease. For example, hemizygous male mice reveal a characteristic "negative electroretinogram" and a highly disorganized retinal architecture with schisis cavities within the inner nuclear layer. This is accompanied by progressive loss of cone and rod photoreceptor cells. ${ }^{10}$ Recently, we have shown that the photoreceptor degeneration is due to apoptosis, more specifically to the receptor mediated extrinsic pathway, with a major burst of dying cells around postnatal day $18 .^{11}$

To elucidate the molecular events that precede photoreceptor disease in the $R s 1 b$ knockout mouse, we applied DNAmicroarray-based mRNA profiling in retinal tissue of postnatal stages $(\mathrm{P}) 7,9,11$, and 14 . Besides $R s 1 \mathrm{~h}$, we identified several differentially expressed transcripts with a functional annotation to adhesion, cytoskeleton, vesicular trafficking, and immune response. Most of the genes in these groups are regulated before the onset of an appreciable expression of genes involved in apoptosis. Notably, many genes are implicated in microglia/glia activity and inflammatory processes. An upregulated expression of the early growth response gene 1 (Egr1) was found relatively early in the disease process at P9. This has further prompted us to investigate the role of Egr1 in RS disease by generating $R s 1 b^{-/ Y} / \mathrm{Egr1}^{-/-}$double-knockout mice.

\section{Materials ANd Methods}

\section{Animals}

Animals were maintained in an air-conditioned environment on a 12-hour light-dark schedule at $20^{\circ} \mathrm{C}$ to $22^{\circ} \mathrm{C}$, and had free access to food and water. The health of the animals was regularly monitored, and all procedures strictly adhered to the ARVO Statement for the Use of Animals in Ophthalmic and Vision Research. The $\mathrm{Egr1}^{+/-}$mouse was purchased from Taconic (Ry, Denmark) and the $R s 1 b^{-/ Y}$ mouse has been described previously. ${ }^{10}$ These mice were on a C57BL/6 background and backcrossed for 12 generations. 
TABLE 1. List of Genes Analyzed by DNA-Microarrays and qRT-PCR Analysis in Mutant $\left(\mathrm{Rs}_{1} \mathrm{~h}^{-/ \mathrm{Y}}\right)$ Versus Wild-Type Retinal Extracts

\begin{tabular}{|c|c|c|c|c|c|}
\hline Age & Unigene ID & $\begin{array}{l}\text { Gene } \\
\text { Symbol }\end{array}$ & Gene Name & Function & $\underset{\text { FC }}{\text { Array }}$ \\
\hline \multirow[t]{19}{*}{$\mathrm{P} 7^{*}$} & Upregulated & & & & \\
\hline & Mm.38049 & $T l r 4$ & Toll-like receptor 4 & Immune response & 4.0 \\
\hline & Mm.17484 & Snca & Synuclein, alpha & Synaptic vesicle protein & $4.0 \mathrm{nc}$ \\
\hline & Mm.3959 & Nell2 & Nel-like 2 homolog (chicken) & Adhesion & 2.3 \\
\hline & Mm.66264 & Stx 6 & Syntaxin 6 & Vesicular traffic & 2.2 \\
\hline & Mm.333349 & Wnk1 & WNK lysine deficient protein kinase 1 & Signaling & 1.9 \\
\hline & Mm.235863 & Rcvrn & Recoverin & Photoreceptor protein & 1.8 \\
\hline & Mm.35650 & Tspan31 & Tetraspanin 31 & Unknown & 1.8 \\
\hline & Mm.201322 & Adnp & Activity-dependent neuroprotective protein & Neuroprotection & 1.8 \\
\hline & Mm.2020 & $\operatorname{Csrp2}$ & Cysteine and glycine-rich protein 2 & Proliferation/differentiation & 1.8 \\
\hline & Mm.233799 & Igfbp 4 & Insulin-like growth factor binding protein 4 & Proliferation/differentiation & 1.8 \\
\hline & Mm.207367 & Zdbbc9 & Zinc finger, DHHC domain containing 9 & Signaling & 1.8 \\
\hline & Mm.1574 & Wasl & Wiskott-Aldrich syndrome-like (human) & Cytoskeleton & 1.8 \\
\hline & Downregulated & & & & \\
\hline & Mm.12145 & Rbbp4 & Retinoblastoma binding protein 4 & Nuclear protein & -1.9 \\
\hline & Mm.3781 & Piga & Phosphatidylinositol glycan, class A & Adhesion & -2.0 \\
\hline & Mm. 4559 & Ggt1 & Gamma-glutamyltransferase 1 & Glutatione metabolism & -2.4 \\
\hline & Mm.332849 & Wasf3 & WAS protein family, member 3 & Cytoskeleton & -2.5 \\
\hline & Mm.41982 & $R s 1 b$ & Retinoschisis 1 homolog (human) & Adhesion & $-3.8 \mathrm{c}$ \\
\hline \multirow[t]{26}{*}{ P9* } & Upregulated & & & & \\
\hline & Mm.92529 & $U b q \ln 2$ & Ubiquilin 2 & Ubiquitin metabolism & 2.0 \\
\hline & Downregulated & & & & \\
\hline & Mm.34405 & Casp3 & Caspase 3 & Apoptosis & -1.8 \\
\hline & Mm.103669 & Cabp5 & Calcium binding protein 5 & Calcium binding & -1.9 \\
\hline & Mm.5061 & Arf2 & ADP-ribosylation factor 2 & Vesicular traffic & -2.1 \\
\hline & Mm.256034 & Cct3 & Chaperonin subunit 3 (gamma) & Chaperon & -2.1 \\
\hline & Mm.378902 & $\mathrm{Cttn}$ & Cortactin & Cytoskeleton & -2.1 \\
\hline & Mm.278357 & Kns2 & Kinesin 2 & Cytoskeleton & -2.2 \\
\hline & Mm.3527 & Cong2 & Cyclin G2 & Cell cycle & -2.2 \\
\hline & Mm.41642 & Rgs4 & Regulator of G-protein signaling 4 & Signaling & -2.3 \\
\hline & Mm.379376 & Syt11 & Synaptotagmin XI & Synaptic vesicle protein & -2.3 \\
\hline & Mm.295284 & Stom & Stomatin & Cytoskeleton & -2.3 \\
\hline & Mm.278865 & Stxbp1 & Syntaxin binding protein 1 & vesicular traffic & -2.3 \\
\hline & Mm.2154 & Mxi1 & Max interacting protein 1 & Transcription factor & -2.5 \\
\hline & Mm.3608 & Pax6 & Paired box gene 6 & Transcription factor & -2.6 \\
\hline & Mm.21281 & Rnf4 & Ring finger protein 4 & Transcription factor & -2.7 \\
\hline & Mm.143603 & Sh $3 g l 2$ & SH3-domain GRB2-like 2 & Vesicular traffic & -2.7 \\
\hline & Mm.3193 & Pkia & Protein kinase inhibitor, alpha & Signaling & -2.7 \\
\hline & Mm.308180 & Ptplad1 & Protein tyrosine phosphatase-like A domain containing 1 & Signaling & -2.7 \\
\hline & Mm.43871 & Trim35 & Tripartite motif-containing 35 & Apoptosis & -2.8 \\
\hline & Mm.4173 & Mtap1b & Microtubule-associated protein $1 \mathrm{~B}$ & Cytoskeleton & -2.8 \\
\hline & Mm.218820 & Dnm1l & Dynamin 1-like & Cytoskeleton & -3.0 \\
\hline & Mm.291928 & Ctnnb1 & Catenin (cadherin associated protein), beta $1,88 \mathrm{kDa}$ & Cytoskeleton & -3.3 \\
\hline & Mm.41982 & Rs1b & Retinoschisis 1 homolog (human) & Adhesion & $-4.1 \mathrm{c}$ \\
\hline & Mm.279256 & Ndrg3 & $\mathrm{N}$-myc downstream regulated gene 3 & Proliferation/differentiation & -4.2 \\
\hline \multirow[t]{23}{*}{ P11* } & Upregulated & & & & \\
\hline & Mm.25168 & Crip3 & Cysteine-rich protein 3 & Immune response & 3.7 \\
\hline & Mm.92529 & Ubqln 2 & Ubiquilin 2 & Ubiquitin metabolism & 2.2 \\
\hline & Mm.38049 & $\operatorname{Tlr} 4$ & Toll-like receptor 4 & Immune response & 2.2 \\
\hline & Mm.181959 & Egr1 & Early growth response 1 & Transcription factor & $2.0 \mathrm{c}$ \\
\hline & Mm.234266 & Sdc2 & Syndecan 2 & Vesicular traffic & 1.9 \\
\hline & Mm.362054 & Pigq & Phosphatidylinositol glycan, class Q & Adhesion & 1.8 \\
\hline & Downregulated & & & & \\
\hline & Mm.263396 & Itgb1 & Integrin beta 1 (fibronectin receptor beta) & Adhesion & -1.8 \\
\hline & Mm.5028 & Inppl1 & Inositol polyphosphate phosphatase-like 1 & Immune response & -1.8 \\
\hline & Mm.256034 & Cct3 & Chaperonin subunit 3 (gamma) & Chaperon & -1.8 \\
\hline & Mm.4950 & Glp2 & Interferon, alpha-inducible protein & Immune response & -1.9 \\
\hline & Mm.253090 & Ap2a2 & Adaptor protein complex AP-2, alpha 2 subunit & Vesicular traffic & -1.9 \\
\hline & Mm.24724 & Ppp1r3c & Protein phosphatase 1 , regulatory (inhibitor) subunit $3 \mathrm{C}$ & Glycogen metabolism & -1.9 \\
\hline & Mm.294821 & 0610042115 & RIKEN cDNA 0610042115 gene & Unknown & -1.9 \\
\hline & Mm.30837 & Ndrg1 & $\mathrm{N}$-myc downstream regulated gene 1 & Differentiation & -1.9 \\
\hline & Mm.1635 & Pias 3 & Protein inhibitor of activated STAT 3 & Immune response & -1.9 \\
\hline & Mm.38993 & Clstn1 & Calsyntenin 1 & Vesicular traffic & -2.0 \\
\hline & Mm.1682 & Ptpns1 & $\begin{array}{l}\text { Protein tyrosine phosphatase, non-receptor type } \\
\text { substrate } 1\end{array}$ & Adhesion & -2.0 \\
\hline & Mm.270484 & Mkrn1 & Makorin, ring finger protein, 1 & Ubiquitin metabolism & -2.0 \\
\hline & Mm.295284 & Stom & Stomatin & Cytoskeleton & -2.0 \\
\hline & Mm.347910 & Ing4 & Inhibitor of growth family, member 4 & Cell cycle & -2.0 \\
\hline & Mm.5061 & $\operatorname{Arf} 2$ & ADP-ribosylation factor 2 & Vesicular traffic & -2.1 \\
\hline
\end{tabular}


TABLE 1 (continued). List of Genes Analyzed by DNA-Microarrays and qRT-PCR Analysis in Mutant (Rs1h ${ }^{-/ Y}$ ) Versus Wild-Type Retinal Extracts

\begin{tabular}{|c|c|c|c|c|c|}
\hline Age & Unigene ID & $\begin{array}{c}\text { Gene } \\
\text { Symbol }\end{array}$ & Gene Name & Function & $\begin{array}{c}\text { Array } \\
\text { FC }\end{array}$ \\
\hline & Mm.332967 & Ube $2 b$ & Ubiquitin-conjugating enzyme E2H & Ubiquitin metabolism & -2.1 \\
\hline & Mm.3781 & Piga & Phosphatidylinositol glycan, class A & Adhesion & -2.1 \\
\hline & Mm.291928 & Ctnnb1 & Catenin (cadherin associated protein), beta $1,88 \mathrm{kDa}$ & Cytoskeleton & -2.2 \\
\hline & Mm.143603 & Sh3gl2 & SH3-domain GRB2-like 2 & Vesicular traffic & -2.3 \\
\hline & Mm.295246 & $4632413 K 17$ & RIKEN cDNA 4632413K17 gene & Unknown & -3.0 \\
\hline & Mm.41982 & Rs $1 b$ & Retinoschisis 1 homolog (human) & Adhesion & $-4.0 \mathrm{c}$ \\
\hline \multirow[t]{43}{*}{ P14† } & \multicolumn{5}{|l|}{ Upregulated } \\
\hline & Mm.288474 & Spp1 & Secreted phosphoprotein 1 & Immune response & $4.3 \mathrm{c}$ \\
\hline & Mm.182785 & Emp1 & Epithelial membrane protein 1 & Adhesion & 2.5 \\
\hline & Mm.100144 & S100a6 & S100 calcium binding protein A6 (calcyclin) & Calcium binding & $2.4 \mathrm{c}$ \\
\hline & Mm.46301 & Tyrobp & TYRO protein tyrosine kinase binding protein & Immune response & $2.3 \mathrm{c}$ \\
\hline & Mm.38498 & Krt1-15 & Keratin complex 1 , acidic, gene 15 & Cytoskeleton & 2.3 \\
\hline & Mm.383993 & $K r t 2-5$ & Keratin complex 2, basic, gene 5 & Cytoskeleton & 2.2 \\
\hline & Mm.239516 & $\mathrm{Clec} 7 a$ & C-type lectin domain family 7 , member a & Macrophage protein & $2.2 \mathrm{c}$ \\
\hline & Mm.175661 & Ifitm1 & Interferon induced transmembrane protein 1 & Immune response & 2.2 \\
\hline & Mm.378931 & Gsto1 & Glutathione S-transferase omega 1 & Detoxification & 2.1 \\
\hline & Mm.15819 & Cd68 & CD68 antigen & Macrophage protein & $2.1 \mathrm{c}$ \\
\hline & Mm.3999 & Mpeg1 & Macrophage expressed gene 1 & Macrophage protein & $2.1 \mathrm{c}$ \\
\hline & Mm.347407 & Cebpd & CCAAT/enhancer binding protein (C/EBP), delta & Transcription factor & 2.1 \\
\hline & Mm.2409 & Adb1 & Alcohol dehydrogenase 1 (class 1 ) & Detoxification & 2.0 \\
\hline & Mm.1282 & $\mathrm{Ccl} 3$ & Chemokine (C-C motif) ligand 3 & Immune response & 2.0 \\
\hline & Mm.45436 & Lyzs & Lysozyme & Immune response & $2.0 \mathrm{c}$ \\
\hline & Mm.355327 & $D s p$ & Desmoplakin & Cytoskeleton & 2.0 \\
\hline & Mm.4646 & Krt1-13 & Keratin complex 1 , acidic, gene 13 & Cytoskeleton & 2.0 \\
\hline & Mm.22673 & Fcer1g & Fc receptor, IgE, high affinity 1 , gamma polypeptide & Macrophage protein & $1.9 \mathrm{c}$ \\
\hline & Mm.1239 & Gfap & Glial fibrillary acidic protein & Cytoskeleton & $1.9 \mathrm{c}$ \\
\hline & Mm.248615 & Lgals3 & Lectin, galactose binding, soluble 3 & Adhesion & 1.9 \\
\hline & Mm.303231 & Cxcl12 & Chemokine (C-X-C motif) ligand 12 & Immune response & 1.9 \\
\hline & Mm.45173 & Msr 2 & Macrophage scavenger receptor 2 & Macrophage protein & $1.9 \mathrm{c}$ \\
\hline & Mm.275715 & 1700063005 & RIKEN cDNA 1700063D05 gene & Unknown & $1.9 \mathrm{c}$ \\
\hline & Mm.42230 & Cур $26 A 1$ & Cytochrome $\mathrm{P} 450$, family 26 , subfamily a, polypeptide 1 & Retinoid metabolism & $1.9 \mathrm{c}$ \\
\hline & Mm.22723 & Gpr126 & G protein-coupled receptor 126 & Signaling & $1.9 \mathrm{nc}$ \\
\hline & Mm.6974 & Krt1-14 & Keratin complex 1 , acidic, gene 14 & Cytoskeleton & 1.9 \\
\hline & Mm.268000 & Vim & Vimentin & Cytoskeleton & 1.8 \\
\hline & Mm.244003 & Scel & Sciellin & Epithelial barrier & 1.8 \\
\hline & Mm.137 & Ccl6 & Chemokine (C-C motif) ligand 6 & Immune response & $1.8 \mathrm{c}$ \\
\hline & Mm.271711 & Tagln 2 & Transgelin 2 & Cytoskeleton & $1.8 \mathrm{c}$ \\
\hline & Mm.2570 & $C 1 q b$ & Complement component $1 \mathrm{q}$, beta polypeptide & Immune response & 1.8 \\
\hline & \multicolumn{5}{|l|}{ Downregulated } \\
\hline & Mm.336111 & Syt1 & Synaptotagmin 1 & Synaptic vesicle protein & -1.8 \\
\hline & Mm.259879 & Birc 4 & Baculoviral IAP repeat-containing 4 & Apoptosis/antiApoptosis & -1.8 \\
\hline & Mm.272264 & Stx 3 & Syntaxin 3 & Vesicular traffic & -1.8 \\
\hline & Mm.218473 & Serinc3 & Srine incorporator 3 & Apoptosis/antiApoptosis & -1.8 \\
\hline & Mm.296520 & Vps35 & Vacuolar protein sorting 35 & Vesicular traffic & -1.8 \\
\hline & Mm.306026 & Epb4.112 & Erythrocyte protein band 4.1-like 2 & Cytoskeleton & -1.9 \\
\hline & Mm.30837 & Ndrg 1 & $\mathrm{~N}$-myc downstream regulated gene 1 & Differentiation & -1.9 \\
\hline & Mm.279923 & Nedd4 & Neural developmentally downregulated gene 4 & Ubiquitin metabolism & -2.1 \\
\hline & Mm.1228 & Cryaa & Crystallin, alpha A & Eye lens protein & -2.2 \\
\hline & Mm.41982 & Rs1b & Retinoschisis 1 homologue (human) & Adhesion & $-3.6 c$ \\
\hline
\end{tabular}

c, confirmed; nc, not confirmed.

${ }^{*}$ Three $R s 1 b^{-/ Y}$ and three wild-type retinal cRNA samples were hybridized to the Mouse Genome 430A 2.0 Array.

† Six $R s 1 b^{-/ Y}$ and seven wild-type retinal cRNA samples were hybridized to the Mouse Genome 4302.0 Array.

\section{RNA Isolation}

Retinal tissue was isolated from eye bulbs and purified under the microscope from contaminating vitreous body and retinal pigment epithelium/choriocapillaris. Total RNA was extracted (RNeasy Mini Kit; Qiagen, Hilden, Germany).

\section{Microarray Analysis and Statistical Data Evaluation}

Generation of double-stranded cDNA, preparation and labeling of cRNA, hybridization to 430A 2.0 or 4302.0 mouse genome arrays (Affymetrix, Santa Clara, CA), washing, and scanning were performed according to the protocol. Scanned images were analyzed (Microarray Suite version 5.0; Affymetrix), to generate report files for quality control. For data analysis, expression levels of single probes derived from Affymetrix CEL-files were evaluated (ChipInspector software; Genomatix GmbH, Munich, Germany). Previous annotations of the single oligonucleotide probes by Affymetrix were disregarded, together with the grouping of the probes in probe sets. The sequence of each single probe was mapped against the current genome annotation (Build 36; National Center for Biotechnology Information [NCBI], Bethesda, MD) and only probes with uniqueness in the genome were used for analysis. Furthermore, single nucleotide polymorphisms were accounted for. Thereafter, ratios of single probe signals were calculated and logarithmic transformation was performed. For normalization, a linear total-intensity normalization algorithm was used. Significantly regulated transcripts were discovered by a single sided permutated $t$-test with a false discovery rate (FDR) calculation using the significance analysis of microarray (SAM) algorithm. ${ }^{12}$ Scores were calcu- 
lated for each gene based on the multiple of expression level changes relative to the standard deviation of repeated measurements. To estimate FDR, nonsense genes were identified by analyzing permutations of the measurements. An FDR of 5\% was chosen in the first step of our statistical analysis and lists of genes that fulfill these criteria for data sets at P7, P9, P11, and P14 are given in Supplementary Tables S1, S2, S3, and S4, respectively (all Supplementary Tables are available online at http://www. iovs.org/cgi/content/full/48/2/891/DC1). To increase stringency, a 1.8 fold-change and a minimum signal intensity of 50 were selected as inclusion criteria (Table 1). ${ }^{13}$ Functional annotation of transcripts was performed on computer (BiblioSphere, Pathway Edition; Genomatix, Munich, Germany). ${ }^{14}$ The microarray data set of this study is publicly available at the NCBI Gene Expression Omnibus (http://www.ncbi.nlm. nih.gov/geo/) through accession number GSE5581.

\section{Quantitative Real-Time RT-PCR Analysis}

Total RNAs from time points P5, P7, P9, P11, P13, P14, P15, P18, and $\mathrm{P} 22$ from $R s 1 b^{-/ \mathrm{Y}}$ mice and RNAs from time points P18 and P24 from $R s 1 b^{-/ Y} / E g r 1^{+/-}$and $R s 1 b^{-/ Y} / E g r 1^{-/-}$mice were used to generate cDNA. For each condition two animals (four eyes) were analyzed in triplicate measurements. First strand cDNA synthesis was performed (Superscript II; Invitrogen, Karlsruhe, Germany). Quantitative real-time RT-PCR (qRT-PCR) was performed with a thermocycler (iCycler; BioRad, Munich, Germany) as described previously, ${ }^{11}$ using primers listed in Supplementary Table S5. Input cDNA quantities were estimated by comparison to expression of five reference genes (Atp5b, Gusb, Hprt1, Rpl4, and Sdba). ${ }^{15}$

\section{SDS Gel Electrophoresis and Western Blot Analysis}

Retinal tissue was homogenized in buffer (PhosphoSafe; Novagen, Madison, WI). Quantitation of protein extracts was performed by a protein assay based on the Bradford method (Bio-Rad). Western blots were prepared after SDS-PAGE of $20 \mu \mathrm{g}$ protein and labeled with phospho-ERK 1/2 pAb (dilution 1:1.000; Sigma-Aldrich, Munich, Germany), ERK 1/2 pAb (dilution 1:2.000; Sigma-Aldrich), or $\beta$-actin mAb (dilution 1:60.000; Sigma-Aldrich). After the blots were washed in PBS/Tween-20, they were labeled with goat anti-rabbit and goat antimouse Ig-peroxidase (dilution 1:10.000; Calbiochem, La Jolla, CA) for detection by enhanced chemiluminescence (ECL).

\section{Immunofluorescence Labeling and TUNEL-Assay}

Immunofluorescence studies of retinal cryosections and TUNEL-staining of eye bulbs from $R s 1 b$-deficient, Egr1-deficient (Taconic) or double-knockout mice $\left(R s 1 b^{-/ Y} / E g r 1^{+/-}\right.$and $\left.R s 1 b^{-/ Y} / E g r 1^{-/-}\right)$was performed exactly as described recently. ${ }^{11}$

\section{Results}

\section{Microarray Analysis}

To study molecular events accompanying retinoschisin deficiency, we first analyzed gene expression in retinal tissues from $R s 1 b$-knockout and wild-type mice at P7, P9, and P11. In wild-type animals, expression of $R s 1 b$ mRNA is detectable at $\mathrm{P} 5$ and reaches adult levels at P11 (data not shown). Retinal cRNAs from three $R s 1 b^{-/ Y}$ mice and three wild-type littermates at $\mathrm{P} 7, \mathrm{P} 9$, and $\mathrm{P} 11$ were hybridized to microarrays (Mouse Genome 430A 2.0 GeneChips; Affymetrix) detecting 14,000 annotated mouse genes. For a second round analysis of stage P14, cRNAs from six Rs $1 b$-knockout mice and seven wild-type littermates were hybridized to microarrays (Mouse Genome 4302.0 GeneChips; Affymetrix) covering more than 34,000 mouse genes.

Initial evaluation of single probe expression ratios with a false discovery rate (FDR) of 5\% based on SAM analysis indicated differential expression of 55 genes on P7, 60 genes on
P9, 87 genes on P11, and 262 genes on P14 (for gene lists see Supplementary Tables S1-S4). Based on own experience with previous microarray studies, ${ }^{13}$ we next applied higher-stringency conditions selecting for genes with at least 1.8 -fold expression changes and minimum signal intensities of 50 signal units. Thereafter, the number of significantly regulated genes was reduced to 17 for $\mathrm{P} 7,24$ for $\mathrm{P} 9,27$ for $\mathrm{P} 11$, and 41 for $\mathrm{P} 14$ (Table 1). The top regulated genes apart from $R s 1 b$ were $T l r 4$ (4.0-fold) and Wasf3 (-2.5-fold) at P7, Ubqln2 (2.0-fold) and Ndrg3 ( -4.2 -fold) at P9, Crip3 (3.7-fold) and the unknown gene $4632413 K 17$ (-3.0-fold) at P11, and Spp1 (4.3-fold) and Cryaa (-2.2-fold) at P14.

To characterize further the observed mRNA regulations, molecular function annotation of pathways was performed. As displayed in Figure 1, grouping of genes into pathways with at least two entries recurring in the time course (colored segments) yielded the main categories cytoskeleton, adhesion, vesicular trafficking, immune response, and apoptosis. At P7, genes involved in adhesion and vesicular trafficking were prominent, whereas at later stages immune response and $\mathrm{mi}-$ croglia/glia-specific genes were mainly detected. Genes regulated at several time points include the induced immune regulatory gene $T l r 4$ and the downregulated vesicular trafficking gene Sh3gl2 (Table 2). All commonly regulated transcripts were found at P11 and we therefore conclude that these molecular events represent initial as well as secondary changes related to $R s 1 b$ deficiency. The large number of upregulated genes at P14 related to immune response also indicates a significant involvement of microglia and glia cells in RS. Because transcription factors are of particular importance for regulatory responses, the upregulation of $E g r 1$ was verified by qRT-PCR along with the immune response genes induced at P14 (Table 1 and Fig. 1). Six transcripts which are increased at P14, namely Spp1, Emp1, S100a6, Lgals3, Cxcl12, and Vim contain verified Egr 1 binding sites in their regulatory regions, suggesting that early Egr 1 expression could induce transcriptional waves at later time points.

\section{Refined Expression Profiling by qRT-PCR and Immunohistochemistry}

We next examined the upregulated transcripts at postnatal stages P7, P9, P11, P13, P15, P18, and P22 by qRT-PCR (Fig. 2). Egr1 was significantly induced in the retinoschisin-deficient retina starting at $\mathrm{P9}(P<0.05)$, further upregulated at $\mathrm{P} 11$ and $\mathrm{P} 13$ ( $P<0.001$ and $P<0.05$, respectively), unchanged at P15, and again strongly induced at P18 and P22 (Fig. 2a). We then quantified mRNA levels of $1700063 D 05$, a gene with an as yet unknown function (Fig. 2b). Upregulation of $1700063 D 05$ transcripts started in $R s 1 b$ knockout mice at P13 but showed a marked decline from P15 to P22. The expression profile 1 in Figure 2c subsumes the mRNA pattern of 10 upregulated genes identified in the DNA-microarray experiments at P14 including Spp1, Tyrobp, Clec7a, Cd68, Ccl6, Fcer1g, Lyzs, Mpeg1, Msr2, and $C d 53$ (Table 1 and Supplementary Table S4) comprising microglia-associated genes. There is a steady increase in gene expression starting between P11 and P13 with a maximum at P18 and a decline beyond this time point. Expression profile 2 (Fig. 2d) represents the expression pattern of five genes including S100a6, Cyp26a1, Tgm2, Tagln2, and Gfap revealing a sharp upregulation between P15 and P18 and elevated levels until P22.

We then sought to define precisely the chronological expression of microglia-associated genes exemplified by $C d 68$ and $C l e c 7 a$ in comparison with transcripts involved in the extrinsic pathway of apoptosis (Casp8 and Tnfrsfo). There was a steady increase of expression profile 1 transcripts beginning at P13 while apoptosis-related upregulation started not until 
17 genes

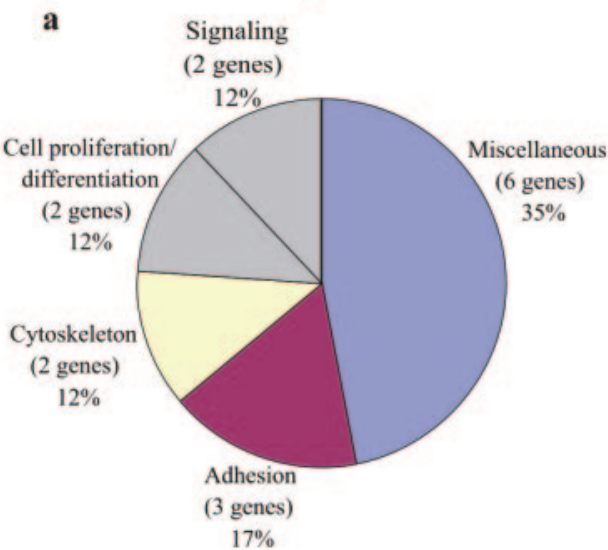

27 genes

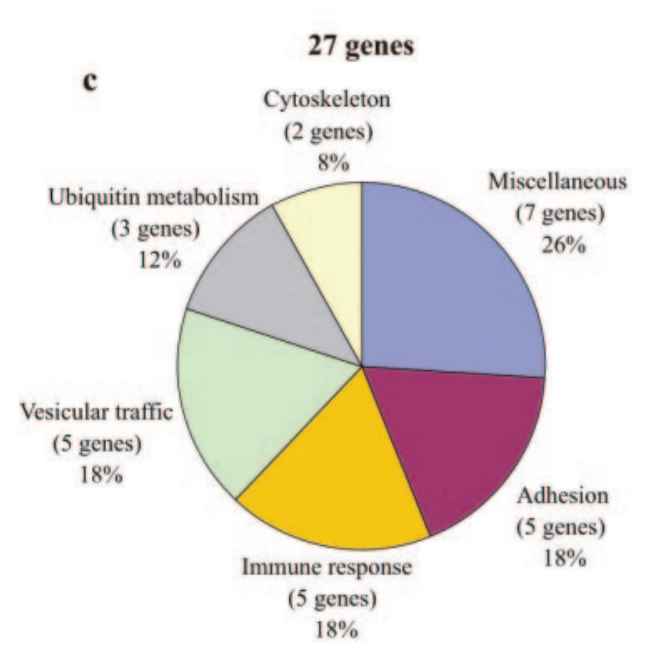

24 genes
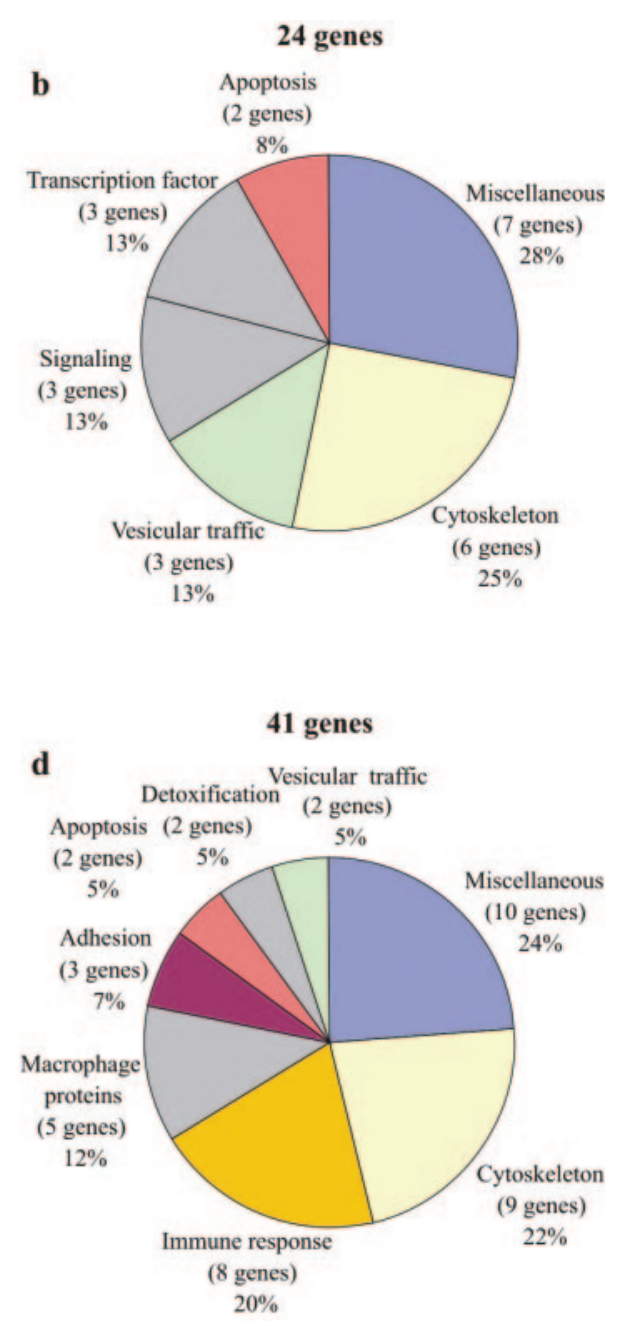

FigURE 1. Molecular function annotation of significantly regulated genes at time points P7 (a), P9 (b), P11 (c), and P14 (d) in retinoschisin-deficient versus wild-type retina. Colored segments: common pathways recurring at different stages; gray segments: unique at one time point. All genes included in these pathways are listed in Table 1.
P16 (Fig. 3). These data clearly indicate that microglia-related gene expression precedes expression of apoptosis-related transcripts in the retinoschisin-deficient retina by several days.

To correlate mRNA profiles with protein expression, we performed immunohistochemistry on $R s 1 b$ knockout and wildtype retinal sections from three developmental stages (P14, $\mathrm{P} 18$, and P24). Anti-F4/80 was used as a marker of microglia activation, whereas the glial fibrillary acidic protein (Gfap) served as a stress indicator of retinal Müller glial cells. At P14, expression of Gfap (green) was similar in the retinoschisindeficient and the wild-type retina, whereas the activation marker $\mathrm{F} 4 / 80$ (red) indicated isolated microglia in the inner nuclear layer of the $R s 1 b^{-/ Y}$ retina (Fig. 4, left). At P18 and P24 there was prominent labeling of the two marker proteins in the $R s 1 b$-knockout tissue (Fig. 4, middle and right) fully corroborating our qRT-PCR data (Figs. 2c, 2d, 3).

\section{Analysis of the Erk1/2 Pathway in the Retinoschisin-Deficient Retina}

Our data demonstrate that upregulation of Egr1 at P9 may contribute to the pathogenesis of the retinoschisin-deficient

TABLE 2. List of Commonly Regulated Genes at Different Stages in Mutant $\left(R s 1 h^{-/ Y}\right)$ versus Wild-Type Retinal Extracts

\begin{tabular}{|c|c|c|c|c|}
\hline Unigene ID & Gene Symbol & Gene Name & $\begin{array}{c}\text { Array } \\
\text { FC }\end{array}$ & Day \\
\hline \multicolumn{5}{|l|}{ Upregulated genes } \\
\hline Mm.38049 & Tlr4 & Toll-like receptor 4 & 2.2 & P7, P11 \\
\hline Mm.92529 & Ubqln2 & Ubiquilin 2 & 2.2 & P9, P11 \\
\hline \multicolumn{5}{|c|}{ Downregulated genes } \\
\hline Mm.256034 & Cct3 & Chaperonin subunit 3 (gamma) & -1.8 & P9, P11 \\
\hline Mm.30837 & $\operatorname{Narg} 1$ & N-myc downstream regulated gene 1 & -1.9 & P11, P14 \\
\hline Mm.5061 & $\operatorname{Arf2}$ & ADP-ribosylation factor 2 & -2.1 & P9, P11 \\
\hline Mm.3781 & Piga & Phosphatidylinositol glycan. class A & -2.1 & $\mathrm{P} 7, \mathrm{P} 11$ \\
\hline Mm.291928 & Ctnnb1 & Catenin (cadherin associated protein), beta $1,88 \mathrm{kDa}$ & -2.2 & P9, P11 \\
\hline Mm.295284 & Stom & Stomatin & -2.3 & P9, P11 \\
\hline Mm.143603 & Sh3gl2 & SH3-domain GRB2-like 2 & -2.3 & P9, P11 \\
\hline Mm.41982 & Rs $1 \mathrm{~b}$ & Retinoschisis 1 homologue (human) & -3.6 & P7-P14 \\
\hline
\end{tabular}




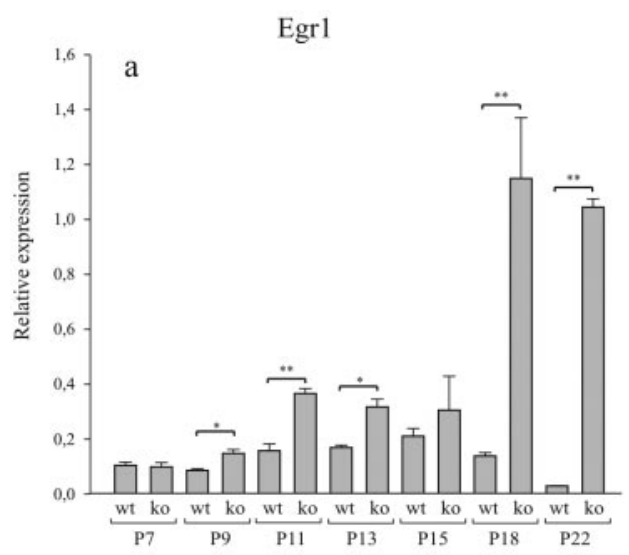

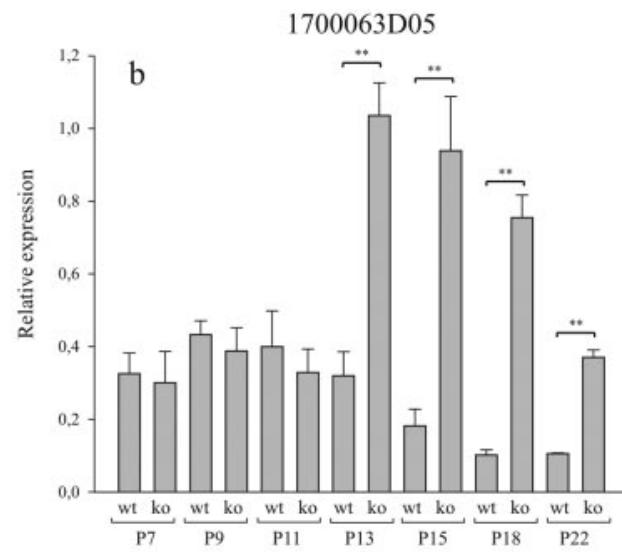

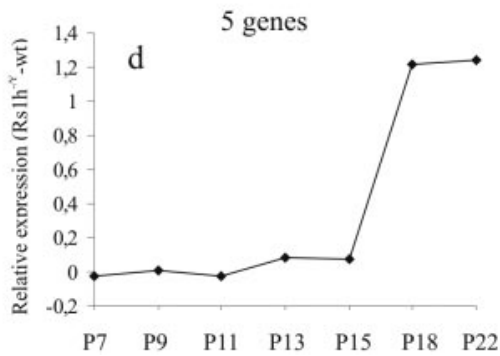

FIGURE 2. Quantitative RT-PCR analysis of differentially regulated genes in the retinoschisin-deficient (ko) versus wild-type (wt) retina. (a) Developmental time course of expression for Egr 1 and (b) for the hypothetical transcript 1700063D05, respectively. (c) Profile 1 depicts the expression pattern of 10 genes, including $\mathrm{Ccl} 6, \mathrm{Cd} 53, \mathrm{Cd} 68$, Clecsf12, Fcer1g, Lyzs, Mpeg1, Msr2, $S p p 1$, and Tyrobp whereas (d) profile 2 comprises five genes, including S100a6, Gfap, Cyp26a1, Tgm2, and Tagln2. The $y$-axis depicts the relative expression levels of the respective genes either separately for $R s 1 b^{-/ Y}$ and wild-type (wt) or for both conditions calculated by subtracting relative expression values of wt from ko. Error bars, SD. Statistical significance is given as ${ }^{*} P<0.05$ or ${ }^{* *} P<0.001$ (Student's $t$-test). Experiments were performed with retinas from two different animals (four eyes) and each were performed in triplicate measurements. retina. Egr1 expression is induced by external signals including growth factors, hormones, neurotransmitters, or toxins via the serine-threonine kinases Erk1 and Erk2 in the mitogen-activated protein kinase (MAPK) pathway. ${ }^{16,17}$ We therefore analyzed the phosphorylation status of Erk1/2 in the $R s 1 b$-deficient retina at stages $\mathrm{P} 5, \mathrm{P} 7, \mathrm{P} 11$, and $\mathrm{P} 13$ (Fig. 5). Western blot analysis revealed a significant increase in Erk1/2 phosphorylation (p-Erk1/2) at P7, P11, and P13 but not at P5 in retinal extracts from retinoschisin-deficient versus wild-type mice (Fig. 5).

\section{Characterization of the $R s 1 b^{-/ Y} / \mathrm{Egr1}^{-/-}$ Double-Knockout Mouse}

To investigate the role of Egr1 in RS, we generated doubleknockout mice deficient for both retinoschisin and Egr1. His-

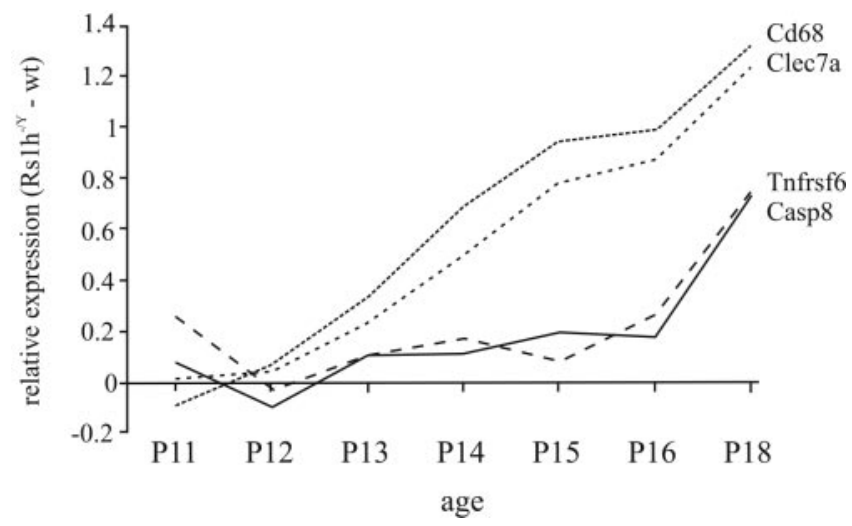

FIGURE 3. Quantitative real-time RT-PCR analysis of macrophage(Cd68 and Clec7a) and apoptosis-related (Tnfrsf6 and Casp8) transcripts. The onset of differential expression in retinoschisin-deficient $\left(\mathrm{Rs}_{1} \mathrm{~h}^{-/ \mathrm{Y}}\right)$ versus wild-type (wt) is distinctly earlier for Cd68 and Clec $7 a$ compared with Tnfrsf6 and Casp8. tologic examination of retinal sections from double knockout mice at P18 and P24 showed pathologic manifestations typical for the single $R s 1 b$ knockout. ${ }^{10}$ Furthermore, three knockout genotypes $\left(R s 1 b^{+/ \mathrm{Y}} / \mathrm{Egr}^{-/-}, R s 1 b^{-/ \mathrm{Y}} / \mathrm{Egr}^{+/-}\right.$, and $R s 1 b^{-/ \mathrm{Y}} /$ $E g r^{-I^{-}}$) were analyzed at P18 and P24 for mRNA expression of the upregulated marker genes 1700063D05, Cd68, and Gfap (Figs. 6a-c). qRT-PCR demonstrates a significant increase of all three transcripts in the $R s 1 b$-deficient retina independent of the Egr1 genotype $\left(E g r 1^{+/-}\right.$or $\left.E g r 1^{-/-}\right)$similar to the data obtained for the $R s 1 b$ single knockout. This suggests that partial or full Egr1 deficiency does not prevent induction of microglia/glia activation markers in the $R s 1 b^{-/ Y}$ retina.

We finally explored possible effects of Egr1-deficiency on the extrinsic apoptotic pathway and identified that the apoptosis markers Tnfrsf6 and Casp 8 are upregulated in the retinoschisin-deficient retina, independent of Egrl expression status $\left(\mathrm{Egrl}^{+/-}\right.$or $\mathrm{Egr1}^{-/-}$; Figs. 6d, 6e). To further corroborate these findings, TUNEL assays were performed in retinal sections of the three genotypes $R s 1 h^{+/ Y} / \mathrm{Egr}^{-/-}, R s 1 b^{-/ \mathrm{Y}}$ $\mathrm{Egr}^{+/-}$, and $\mathrm{Rs} \mathrm{h}^{-/ \mathrm{Y}} / \mathrm{Egr}^{-/-}$at developmental stages P18 and P24. The number of apoptotic nuclei was significantly increased in $R s 1 b^{-/ Y}$ versus wild-type retinas, either on the $\operatorname{Egrl}^{+/-}$or the $\mathrm{Egrl}^{-/-}$background (Fig. 7). This suggests no direct link between transcriptional Egr1 upregulation and apoptotic events in the retinoschisin-deficient mouse.

\section{Discussion}

In the present study, we performed microarray analysis and qRT-PCR in the $R s 1 b^{-/ Y}$ retina compared with wild-type. At $\mathrm{P} 7$, where $R s 1 b$ is normally present and where early events in pathogenesis are expected, transcripts for adhesion molecules, photoreceptor-specific proteins, cytoskeleton, and neuroprotective proteins were detected. Among these, Nell2 is a neuron-specific secreted glycoprotein protecting against oxygenglucose-deprivation- and $\beta$-amyloid-induced cell death, ${ }^{18}$ whereas overexpression of the photoreceptor protein recov- 
P14

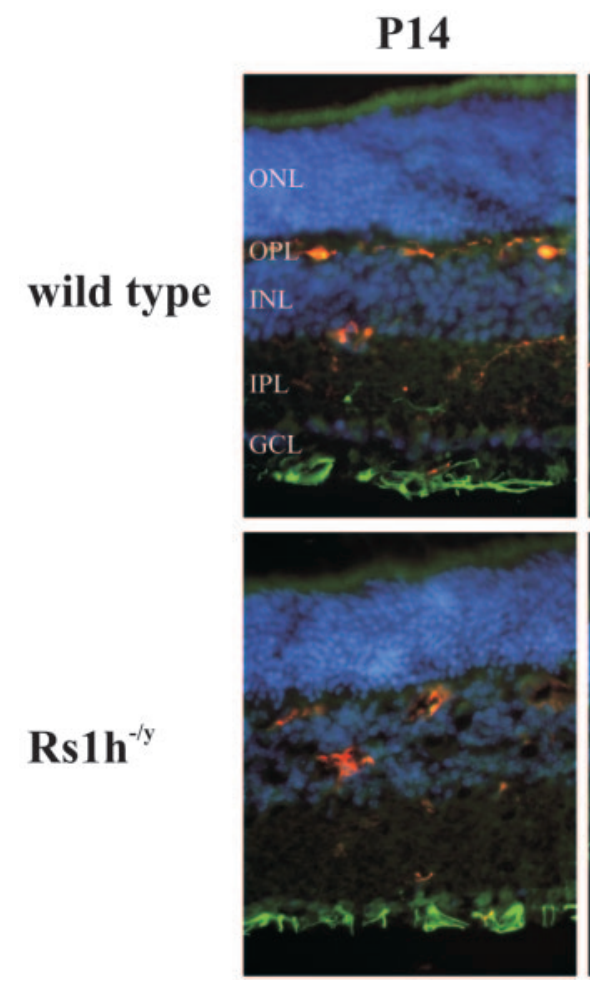

wild type

Figure 4. Immunofluorescence microscopy on cryosections of $R s 1 b^{-/ Y}$ and wild-type mouse retinas at P14, $\mathrm{P} 18$, and P24. Macrophages-microglia were stained with the specific marker $\mathrm{F} 4 / 80$ (red), showing initial macrophage activation at P14 and more prominent labeling at postnatal day P18 and P24 in the $R s 1 b^{-/ Y}$ retina. Müller glial cells are stained with the GFAP antibody (green). Retinal sections of $R s 1 b$ knockout retina reveal cellular disorganization and small cavities starting at P14. Retinal layers are shown in the wild-type P14 image: outer nuclear layer (ONL), outer plexiform layer (OPL), inner nuclear layer (INL), inner plexiform layer (IPL), and ganglion cell layer (GCL).
P18
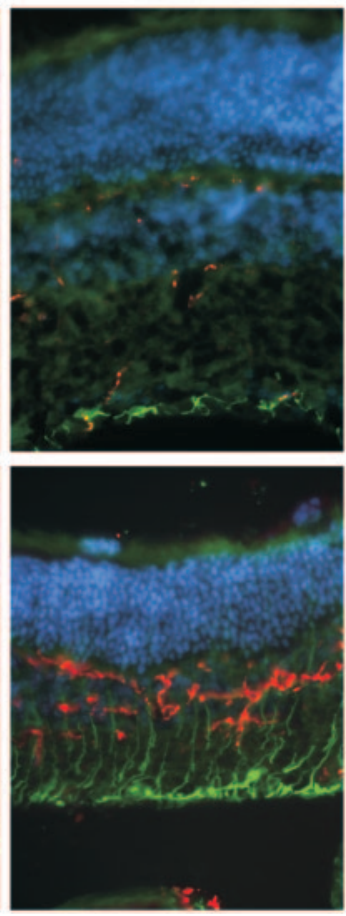

P24
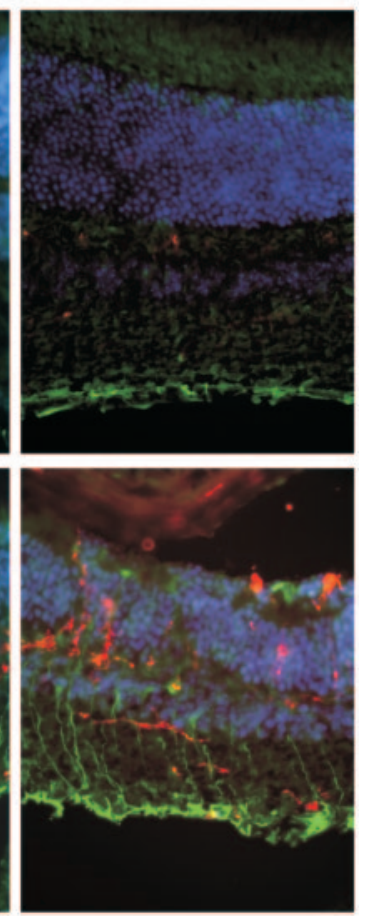

erin leads to photoreceptor degeneration. ${ }^{19}$ The strongest upregulated gene at $\mathrm{P} 7, \operatorname{Tl} 4$, is expressed in retinal pigment epithelium ${ }^{20}$ and in activated microglia. ${ }^{21}$ Furthermore, human TLR 4 genetic variants are associated with age-related macular degeneration, ${ }^{22}$ suggesting functional consequences of these aberrant transcript patterns.

We have identified 10 genes gradually increasing in expression starting at P11 (profile 1), a steep upregulation of $1700063 D 05$ at P13, and induction of five genes in profile 2 (1700063D05, Cyp26a, S100a6, Tagln2, and Gfap) between P15 and P18. Notably, P14 is a time point where first histopathological features such as cystlike structures in the inner retina, disruption of the outer plexiform layer, and disorganization and displacement of retinal cells become apparent in $R s 1 b^{-/ Y}$ animals. ${ }^{10}$ Although $1700063 D 05$ is of unknown function, Cyp26a1 plays a role in retinoic acid metabolism, ${ }^{23}$ $S 100 a 6$ is functionally involved in cell cycle progression, ${ }^{24,25}$ and Tagln 2 represents a marker of smooth muscle differentia-

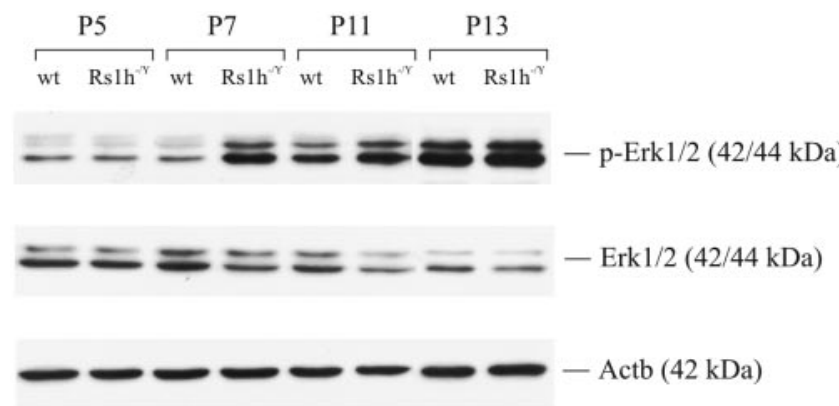

FIGURE 5. Western blot analysis of phosphorylated Erk1/2 (pErk1/2) and nonphosphorylated Erk1/2 (Erk1/2) performed on retinal protein extracts from single $R s 1 b$-deficient $\left(R s 1 b^{-/ Y}\right)$ and wild-type (wt) mice at P5, P7, P11, and P13. In comparison to the wild-type extracts, increased expression levels of pErk1/2 are apparent at P7 and P11 in the retinoschisin-deficient samples. The blot was reprobed with an anti- $\beta$-actin (Actb) antibody as a loading control. tion. ${ }^{26}$ Whereas a correlation between RS and upregulation of transcripts $1700063 D 05, C y p 26 a, S 100 a 6$, and Tagln 2 may be challenging to reconcile, increased expression of the intermediate filament protein Gfap most likely represents a reactive response of Müller glia cells and astrocytes to the degenerative processes caused by the lack of retinoschisin. Accordingly, consistent upregulation of Gfap in other models of retinal injury has been reported, including glaucoma, ${ }^{27,28}$ retinal tear injury, ${ }^{29}$ and diabetic retinopathy. ${ }^{30}$

The expression data at time points P11 and P14 clearly implicate microglia-mediated processes in pathologic events of retinoschisin deficiency. Several genes are related to immune response and are expressed in microglia. Clec $7 a$ is a patternrecognition receptor detecting $\beta$-glucans from fungi and plants, resulting in inflammation ${ }^{31,32}$ and Fcer $1 g$ encodes the gamma chain of the IgE receptor $\mathrm{CD} 23$, which is important for allergic reactions. ${ }^{33}$ Lysz is an inducible marker of phagocytosis expressed during microglia activation after neuronal injury. ${ }^{34}$ The chemokine $\mathrm{Ccl} 6$ acts as mediator of astrocyte and microglia migration in vitro, ${ }^{35}$ whereas the secreted phosphoprotein Spp1, participates in cellular attachment. ${ }^{36}$ Egr1 induces the expression of inflammatory mediators such as TNF- $\alpha$ or macrophage inflammatory protein-2 (MIP-2). ${ }^{16,37,38}$ Egr1, together with Tyrobp, also controls terminal differentiation and activation of macrophages. ${ }^{39-42}$

Several of these immune-regulatory genes (e.g., Spp1, Lysz, and $C 1 q b$ ) and the immediate early response gene Egr 1 have also been associated with retinal disease in DNA-microarray approaches similar to those used in our study, such as analyses of ischemic injury and light-induced damage to the retina. ${ }^{43-45}$ Egr1, which is upregulated at P9 is involved in a large number of cellular events ranging from mitogenesis, differentiation, cell protection and survival, pro- and antiapoptotic processes to macrophage differentiation. ${ }^{40,46}$ Although not unique to retinoschisin-deficiency, this suggests that Egr 1 may act as a convergence point for multiple signaling cascades, which is also supported by our finding that the promoters of six commonly induced genes at P14 related to adhesion, immune response, 
a 1700063D05
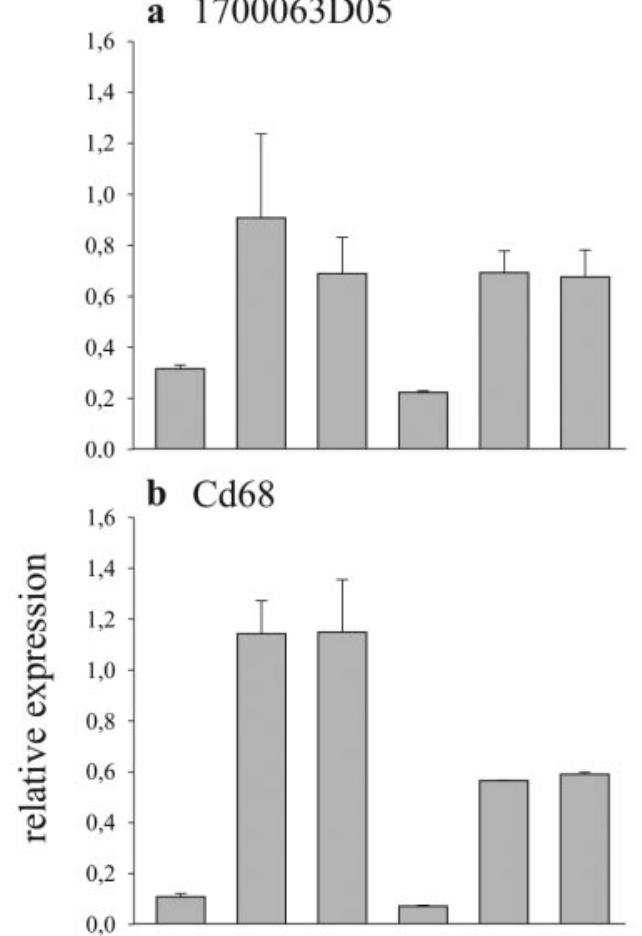

c Gfap

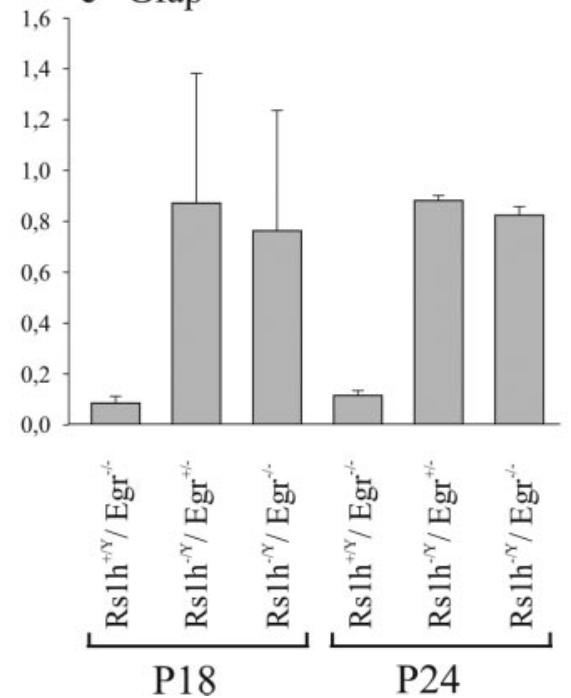

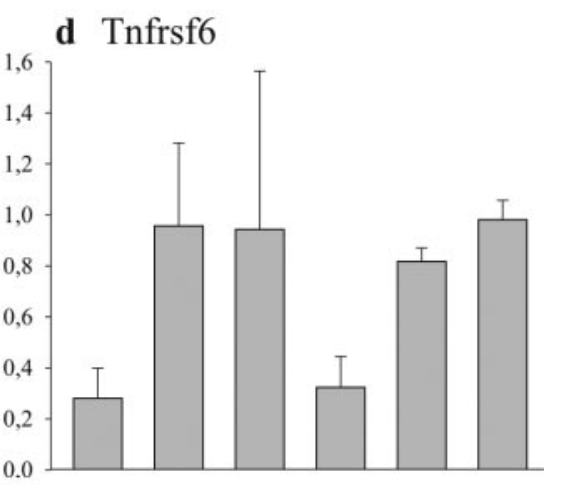
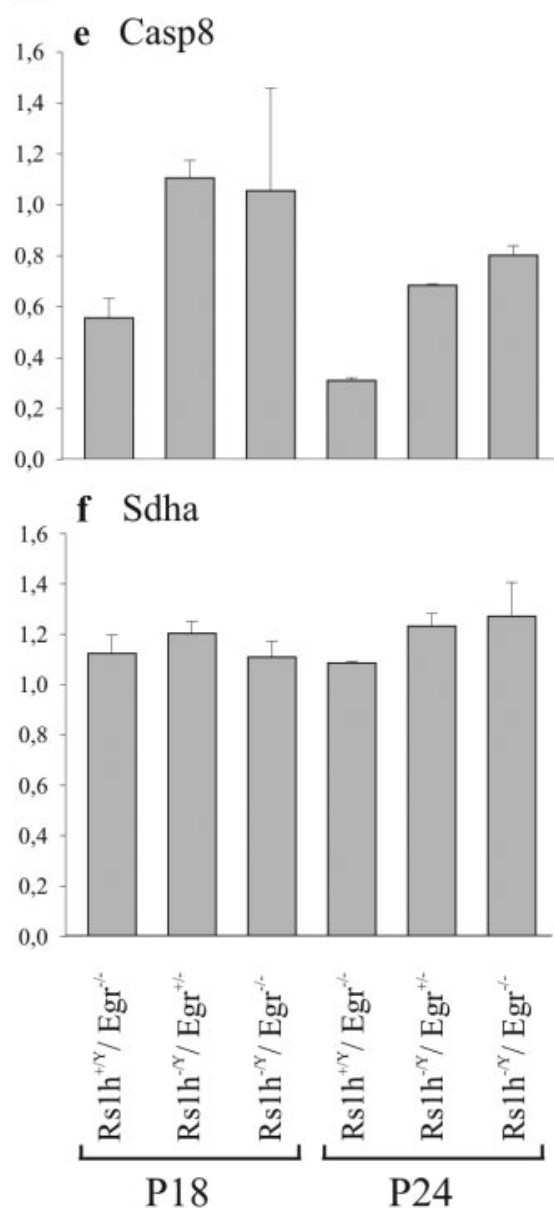

FIGURE 6. Quantitative real-time RTPCR analysis of $1700063 D 05, C d 68$, and Gfap as well as genes involved in the extrinsic pathway of apoptosis (Tnfrsf6 and Casp8) in retinal extracts from three mouse genotypes $R s 1 b^{+/ Y} / \mathrm{Egr1}^{-/-}, \mathrm{Rs} 1 \mathrm{~b}^{-/ Y} / \mathrm{Egrl}^{+/-}$, and $R s 1 b^{-Y Y} / E_{g r 1^{-/-}}$. The analysis was done for two stages at P18 and P24, respectively. Expression of succinate dehydrogenase subunit A (Sdha) serves as control for cDNA integrity. Experiments were performed with retinas from two different animals (four eyes) and were performed in triplicate measurements. and cytoskeleton contain verified Egr1-binding sites. It is therefore of great interest to identify further the events upstream and downstream of the initiation of Egr 1 transcription. Toward this end, we analyzed the phosphorylation of the MAP Erk1/2 kinases and have found that this pathway was activated in the retinoschisin-deficient retina as early as $\mathrm{P} 7$. In mammalian cells, the MEK1/2/ERK signaling pathway plays a crucial role in immediate early gene (IEG) induction by directly activating IEG promoter-bound transcription factors such as Egr $1 .{ }^{47}$ Further studies are needed to determine Egr1-expressing cell types in the diseased retina and to analyze the gene activation cascade upstream of Egr1. So far, the mechanism coupling the extracellular membrane-associated retinoschisin to intracellular signaling remains elusive, but it may be relayed via an as yet unknown membrane receptor protein.

We were also interested in exploring downstream consequences of Egr 1 activation. However, double-knockout mice deficient of both Rs1b and Egr1 were indistinguishable from
$R s 1 b$ single-knockout mice, specifically with regard to retinal histology and expression profiles of microglia/glia- and apoptosis-related transcripts. Our experiments are in line with findings demonstrating that $E g r 1^{-/-}$mice have no obvious defects in macrophage differentiation. ${ }^{48,49}$ However, data from an antisense strategy demonstrate that Egr1 is essential for cell growth and macrophage differentiation. ${ }^{40,50,51}$ These controversial results may be explained by functional redundancy of remaining family members Egr2, Egr3, and Egr4 which are often coordinately regulated. ${ }^{52}$ To further unravel the role of Egr1 in retinoschisin-deficiency, it may therefore be necessary to simultaneously target several $\mathrm{Egr}$ genes.

Commonly, programmed cell death is thought to activate microglia cells resulting in the clearance of dying cells, ${ }^{53}$ although in some cases macrophage stimulation conversely has been demonstrated to trigger apoptosis. ${ }^{54-56}$ We recently reported that postnatal photoreceptor cell death in the $R s 1 b^{-/ Y}$ knockout mouse is due to extrinsic apoptosis at P18. ${ }^{11}$ We 


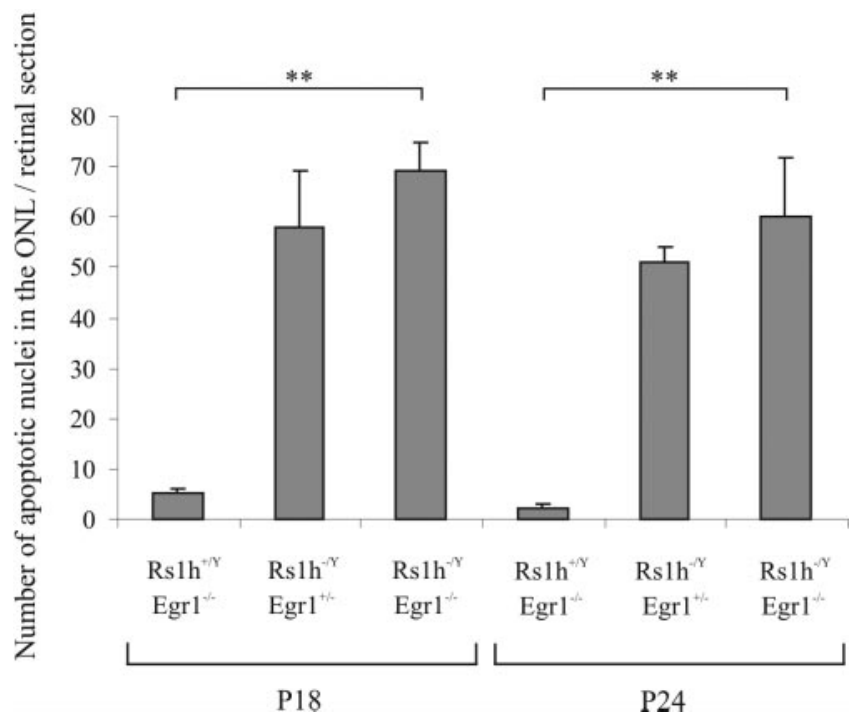

FIGURE 7. TUNEL nuclei count for postnatal stages P18 and P24 indicates that apoptosis in the outer nuclear layer $(\mathrm{ONL})$ depends on the $R s 1 h$ genotype but not on the $\operatorname{Egr} 1$ genotype $\left({ }^{* *} P<0.001\right.$, Student's $t$-test). Each column represents the mean of apoptotic nuclei counted in three retinal sections from three animals at P18 and P24, respectively.

have now defined the relative time course of microglia- and apoptosis-related events in this model and show that the two events can be unambiguously separated. Whereas immunerelated genes are upregulated starting as early as P11, apoptosis-associated transcripts are increased in the $R s 1 b$-deficient retina only after P16. We therefore conclude that microglia activation precedes the onset of apoptotic cell death and may even be involved in triggering apoptosis in the diseased retina.

The goal of the study was to analyze molecular events caused by retinoschisin-deficiency in a mouse model for RS. Our findings indicate activation of the Erk1/2 pathway at P7 followed by an upregulation of transcription factor Egr1 at P9. Functional clustering highlights key pathways including adhesion, cytoskeleton, vesicular trafficking and glia-cell related immune responses. As apoptosis-related gene expression in the retinoschisin-deficient retina is not initiated before P16, we hypothesize that microglia/glia-mediated processes precede and may even cause events of programmed photoreceptor cell death.

\section{Acknowledgments}

The authors thank Heidi Schulz for help with the Exiqon Probe Library Kit.

\section{References}

1. Kellner U, Brummer S, Foerster MH, Wessing A. X-linked congenital retinoschisis. Graefes Arch Clin Exp Ophthalmol. 1990;228: 432- 437 .

2. Sauer CG, Gehrig A, Warneke-Wittstock R, et al. Positional cloning of the gene associated with X-linked juvenile retinoschisis. Nat Genet. 1997;17:164-170.

3. Wu WW, Molday RS. Defective discoidin domain structure, subunit assembly, and endoplasmic reticulum processing of retinoschisin are primary mechanisms responsible for X-linked retinoschisis. J Biol Chem. 2003;278:28139-28146.

4. Grayson C, Reid SN, Ellis JA, et al. Retinoschisin, the X-linked retinoschisis protein, is a secreted photoreceptor protein, and is expressed and released by Weri-Rb1 cells. Hum Mol Genet. 2000; 9:1873-1879.
5. Molday LL, Hicks D, Sauer CG, Weber BH, Molday RS. Expression of X-linked retinoschisis protein RS1 in photoreceptor and bipolar cells. Invest Ophthalmol Vis Sci. 2001;42:816-825.

6. Reid SN, Farber DB. Glial transcytosis of a photoreceptor-secreted signaling protein, retinoschisin. Glia. 2005;49:397- 406.

7. Wu WW, Wong JP, Kast J, Molday RS. RS1, a discoidin domaincontaining retinal cell adhesion protein associated with X-linked retinoschisis, exists as a novel disulfide-linked octamer. $J$ Biol Chem. 2005;280:10721-10730.

8. Baumgartner S, Hofmann K, Chiquet-Ehrismann R, Bucher P. The discoidin domain family revisited: new members from prokaryotes and a homology-based fold prediction. Protein Sci. 1998;7:16261631.

9. Vogel W. Discoidin domain receptors: structural relations and functional implications. FASEB J. 1999;13(suppl):S77-S82.

10. Weber BH, Schrewe H, Molday LL, et al. Inactivation of the murine $\mathrm{X}$-linked juvenile retinoschisis gene, Rs1h, suggests a role of retinoschisin in retinal cell layer organization and synaptic structure. Proc Natl Acad Sci USA. 2002;99:6222-6227.

11. Gehrig A, Janssen A, Horling F, Grimm C, Weber BH. The role of caspases in photoreceptor cell death of the retinoschisin-deficient mouse. Cytogenet Genome Res. 2006;115:35-44.

12. Tusher VG, Tibshirani R, Chu G. Significance analysis of microarrays applied to the ionizing radiation response. Proc Natl Acad Sci USA. 2001;98:5116-5121.

13. Langmann $\mathrm{T}$, Moehle $\mathrm{C}$, Mauerer $\mathrm{R}$, et al. Loss of detoxification in inflammatory bowel disease: dysregulation of pregnane $\mathrm{X}$ receptor target genes. Gastroenterology. 2004; 127:26-40.

14. Seifert M, Scherf M, Epple A, Werner T. Multievidence microarray mining. Trends Genet. 2005;21:553-558.

15. Vandesompele J, De PK, Pattyn F, et al. Accurate normalization of real-time quantitative RT-PCR data by geometric averaging of multiple internal control genes. Genome Biol. 2002;3:RESEARCH0034.

16. Thiel G, Cibelli G. Regulation of life and death by the zinc finger transcription factor Egr-1. J Cell Physiol. 2002;193:287-292.

17. Shin SY, Kim SY, Kim JH, et al. Induction of early growth response-1 gene expression by calmodulin antagonist trifluoperazine through the activation of Elk-1 in human fibrosarcoma HT1080 cells. J Biol Chem. 2001;276:7797-7805.

18. Aihara K, Kuroda S, Kanayama N, Matsuyama S, Tanizawa K, Horie M. A neuron-specific EGF family protein, NELL2, promotes survival of neurons through mitogen-activated protein kinases. Brain Res Mol Brain Res. 2003;116:86-93.

19. Adamus G, Ortega H, Witkowska D, Polans A. Recoverin: a potent uveitogen for the induction of photoreceptor degeneration in Lewis rats. Exp Eye Res. 1994;59:447-455.

20. Kindzelskii AL, Elner VM, Elner SG, Yang D, Hughes BA, Petty HR. Toll-like receptor 4 (TLR4) of retinal pigment epithelial cells participates in transmembrane signaling in response to photoreceptor outer segments. J Gen Physiol. 2004;124:139-149.

21. Kim DC, Kim SH, Jeong MW, Baek NI, Kim KT. Effect of rottlerin, a PKC-delta inhibitor, on TLR-4-dependent activation of murine microglia. Biochem Biophys Res Commun. 2005;337:110-115.

22. Zareparsi S, Buraczynska M, Branham KE, et al. Toll-like receptor 4 variant D299G is associated with susceptibility to age-related macular degeneration. Hum Mol Genet. 2005;14:1449-1455.

23. Ross SA, McCaffery PJ, Drager UC, De Luca LM. Retinoids in embryonal development. Physiol Rev. 2000;80:1021-1054.

24. Ferrari S, Calabretta B, deRiel JK, et al. Structural and functional analysis of a growth-regulated gene, the human calcyclin. $J$ Biol Chem. 1987;262:8325-8332.

25. Tsoporis JN, Marks A, Haddad A, O'Hanlon D, Jolly S, Parker TG. S100A6 is a negative regulator of the induction of cardiac genes by trophic stimuli in cultured rat myocytes. Exp Cell Res. 2005;303: 471-481.

26. Stanier P, bu-Hayyeh S, Murdoch JN, Eddleston J, Copp AJ. Paralogous sm22alpha (Tagln) genes map to mouse chromosomes 1 and 9: further evidence for a paralogous relationship. Genomics. 1998; 51:144-147.

27. Ahmed F, Brown KM, Stephan DA, Morrison JC, Johnson EC, Tomarev SI. Microarray analysis of changes in mRNA levels in the rat retina after experimental elevation of intraocular pressure. Invest Ophthalmol Vis Sci. 2004;45:1247-1258. 
28. Steele MR, Inman DM, Calkins DJ, Horner PJ, Vetter ML. Microarray analysis of retinal gene expression in the DBA/2J model of glaucoma. Invest Ophthalmol Vis Sci. 2006;47:977-985.

29. Vazquez-Chona F, Song BK, Geisert EE Jr. Temporal changes in gene expression after injury in the rat retina. Invest Opbthalmol Vis Sci. 2004;45:2737-2746.

30. Gerhardinger C, Costa MB, Coulombe MC, Toth I, Hoehn T, Grosu P. Expression of acute-phase response proteins in retinal Müller cells in diabetes. Invest Ophthalmol Vis Sci. 2005;46:349-357.

31. Brown GD, Gordon S. Immune recognition of fungal beta-glucans Cell Microbiol. 2005;7:471-479.

32. Brown GD, Taylor PR, Reid DM, et al. Dectin-1 is a major betaglucan receptor on macrophages. J Exp Med. 2002;196:407-412.

33. Rosenwasser LJ, Meng J. Anti-CD23. Clin Rev Allergy Immunol. 2005;29:61-72

34. Venezie $\mathrm{RD}$, Toews $\mathrm{AD}$, Morell $\mathrm{P}$. Macrophage recruitment in different models of nerve injury: lysozyme as a marker for active phagocytosis. J Neurosci Res. 1995;40:99-107.

35. Kanno M, Suzuki S, Fujiwara T, et al. Functional expression of CCL6 by rat microglia: a possible role of CCL6 in cell-cell communication. J Neuroimmunol. 2005;167:72-80.

36. Rittling SR, Denhardt DT. Osteopontin function in pathology: lessons from osteopontin-deficient mice. Exp Nepbrol. 1999;7: 103-113.

37. Yao J, Mackman N, Edgington TS, Fan ST. Lipopolysaccharide induction of the tumor necrosis factor-alpha promoter in human monocytic cells: regulation by Egr-1, c-Jun, and NF-kappaB transcription factors. J Biol Chem. 1997;272:17795-17801.

38. Yan SF, Fujita T, Lu J, et al. Egr-1, a master switch coordinating upregulation of divergent gene families underlying ischemic stress. Nat Med. 2000;6:1355-1361.

39. Ientile R, Merendino RA, Fabiano C, Di Giorgio RM, Macaione S Polyamines are involved in retinoic acid-mediated induction of tissue transglutaminase in human peripheral blood monocytes. Res Commun Chem Patbol Pharmacol. 1992;77:313-326.

40. Krishnaraju K, Nguyen HQ, Liebermann DA, Hoffman B. The zinc finger transcription factor Egr-1 potentiates macrophage differentiation of hematopoietic cells. Mol Cell Biol. 1995;15:5499-5507.

41. Aoki N, Kimura S, Takiyama Y, et al. The role of the DAP12 signal in mouse myeloid differentiation. I Immunol. 2000;165:37903796.

42. Krishnaraju K, Hoffman B, Liebermann DA. Early growth response gene 1 stimulates development of hematopoietic progenitor cells along the macrophage lineage at the expense of the granulocyte and erythroid lineages. Blood. 2001;97:1298-1305.

43. Chen L, Wu W, Dentchev T, et al. Light damage induced changes in mouse retinal gene expression. Exp Eye Res. 2004;79:239-247.

44. Rattner A, Nathans J. The genomic response to retinal disease and injury: evidence for endothelin signaling from photoreceptors to glia. J Neurosci. 2005;25:4540-4549.

45. Yoshimura N, Kikuchi T, Kuroiwa S, Gaun S. Differential temporal and spatial expression of immediate early genes in retinal neurons after ischemia-reperfusion injury. Invest Opbthalmol Vis Sci. 2003; 44:2211-2220

46. Adamson ED, Mercola D. Egr1 transcription factor: multiple roles in prostate tumor cell growth and survival. Tumour Biol. 2002; 23:93-102.

47. Whitmarsh AJ, Shore P, Sharrocks AD, Davis RJ. Integration of MAP kinase signal transduction pathways at the serum response element. Science. 1995;269:403-407.

48. Lee SL, Tourtellotte LC, Wesselschmidt RL, Milbrandt J. Growth and differentiation proceeds normally in cells deficient in the immediate early gene NGFI-A. J Biol Chem. 1995;270:9971-9977.

49. Lee SL, Wang Y, Milbrandt J. Unimpaired macrophage differentiation and activation in mice lacking the zinc finger transplantation factor NGFI-A (EGR1). Mol Cell Biol. 1996;16:4566-4572.

50. Nguyen HQ, Hoffman-Liebermann B, Liebermann DA. The zinc finger transcription factor Egr-1 is essential for and restricts differentiation along the macrophage lineage. Cell. 1993;72:197-209.

51. Perez-Castillo A, Pipaon C, Garcia I, Alemany S. NGFI-A gene expression is necessary for $\mathrm{T}$ lymphocyte proliferation. $\mathrm{J} \mathrm{Biol}$ Chem. 1993;268:19445-19450.

52. Sukhatme VP. The Egr family of nuclear signal transducers. Am J Kidney Dis. 1991;17:615-618.

53. Gupta N, Brown KE, Milam AH. Activated microglia in human retinitis pigmentosa, late-onset retinal degeneration, and age-related macular degeneration. Exp Eye Res. 2003;76:463-471.

54. Lang R, Lustig M, Francois F, Sellinger M, Plesken H. Apoptosis during macrophage-dependent ocular tissue remodelling. Development. 1994;120:3395-3403.

55. Diez-Roux G, Lang RA. Macrophages induce apoptosis in normal cells in vivo. Development. 1997;124:3633-3638.

56. Lobov IB, Rao S, Carroll TJ, et al. WNT7b mediates macrophageinduced programmed cell death in patterning of the vasculature. Nature. 2005;437:417-421. 